Manuscript title: Assessing Collaborative Learning: big data, analytics and university futures

Author: Dr Peter Williams

Address: Faculty of Education, University of Hull, Scarborough Campus, Filey Road, Scarborough YO11 3AZ, UK

Telephone: $+44(0) 1723357219$

Email: p.j.williams@hull.ac.uk

Biographical note: Dr Peter Williams is Senior Lecturer in Technology Enhanced Learning at the University of Hull, UK. He is a University Teaching Fellow and Senior Fellow of the UK Higher Education Academy. His research interests include technology-aided assessment, blended learning, learning environment design and the implications of new technologies for institutional change in Higher Education. 


\title{
Assessing Collaborative Learning: big data, analytics and university futures
}

\author{
Abstract \\ Traditionally, assessment in higher education has focused on the performance of \\ individual students. This focus has been a practical as well as an epistemic one: methods \\ of assessment are constrained by the technology of the day, and in the past they \\ required the completion by individuals under controlled conditions, of set-piece \\ academic exercises. Recent advances in learning analytics, drawing upon vast sets of \\ digitally-stored student activity data, open new practical and epistemic possibilities for \\ assessment and carry the potential to transform higher education. It is becoming \\ practicable to assess the individual and collective performance of team members working \\ on complex projects that closely simulate the professional contexts that graduates will \\ encounter. In addition to academic knowledge this authentic assessment can include a \\ diverse range of personal qualities and dispositions that are key to the computer- \\ supported cooperative working of professionals in the knowledge economy. This paper \\ explores the implications of such opportunities for the purpose and practices of \\ assessment in higher education, as universities adapt their institutional missions to \\ address $21^{\text {st }}$ Century needs. The paper concludes with a strong recommendation for \\ university leaders to deploy analytics to support and evaluate the collaborative learning \\ of students working in realistic contexts.
}

Keywords: social learning analytics; situated learning; collaborative learning; authentic assessment 


\section{Introduction}

Three significant and inter-related issues for higher education will be examined in this paper.

The first issue is the rise of knowledge working within professional occupations in the $21^{\text {st }}$ Century and the challenges this poses to universities. Key to success in knowledge working is the ability to operate as a team member to manage rapidly-updating information over online networks. The qualities required are soft skills and facility in computer-supported cooperative working. Universities have traditionally been the curators of formal, propositional knowledge, focusing their curricula on the transmission and assessment of this through academic performance. The changing demands of preparing students for markedly different professional occupations are compounded by the challenges of working with increasingly transient knowledge.

The second issue to be examined relates to the pedagogic approach of authentic learning: variously described as 'real world' learning, learning applied in realistic contexts or learning-by-doing. It is contrasted from traditional pedagogy by having a greater focus on 'just-in-time' learning. The situating of learning in real or realistic contexts involves students directly in the experience of knowledge working and computer-supported collaborative learning (it should be noted that this is the educational equivalent of computer-supported cooperative working, and in this paper the terms cooperative and collaborative are used synonymously). The benefits of authentic learning can be considerable, but the range of environments and experiences in which they are situated is so diverse as to make their assessment problematic and time consuming.

The final issue for examination in the paper is the opportunities provided by learning analytics to bring authentic assessment (also known as alternative assessment) - and so authentic learning - further into mainstream higher education. The purpose of the paper is not to advocate the use of learning analytics across the board but to consider its potential in supporting a shift in focus from the assessment of individual students' performance in isolation to the assessment of their performance as team players. As a rider to this analysis is a strong recommendation for university leaders to deploy 
analytics not to exercise restrictive management and control over individual students' learning but to support and evaluate their collaborative working in realistic contexts.

\section{Cooperative working in the Knowledge Economy}

\section{Epistemic issues underpinning cooperative working}

Attempts to define the nature of knowledge have typically taken the form of dichotomies. Philosophers in Ancient Greece distinguished between epistêmê and technê: broadly, knowledge-that and knowledge-how, and similar classifications are to be found in Schön's (1983) propositional and procedural knowledge, with the first being formal and codified and the second defined in terms of application. In relation to higher education, Barnett's (2000) contemplative and performative knowledge make a similar distinction, but perhaps the Mode 1 / Mode 2 distinction identified by Gibbons et al. (1994) provides the best fit with discussion later in this paper. According to the authors, the characteristics of Mode 1 knowledge include location within an academic discipline; relative homogeneity and autonomy; and quality control by academic peer review. By contrast, Mode 2 knowledge is located within its context of application (for example, the learning of perioperative practice in hospitals); it is likely to be more transdisciplinary; relatively heterogeneous; socially accountable rather than autonomous; and employing novel forms of quality control. As Usher (2010) observes, Mode 2 knowledge is socially distributed across a relatively large number of work-based user-producers rather than curated within universities or other formal institutions by a relatively small number of discipline specialists. For Nowotny (2003), this socially robust knowledge is the result of a 'democratising of expertise'. A rough analogy is the distinction between Encyclopedia Britannica and Wikipedia, with the latter comprised of multiply-authored articles created by volunteers and subject to continual change. Although the Mode 1 / Mode 2 duality has been criticised (for example, Hessels and van Lente 2008) and alternative models proposed to explain the rise of 'non-official knowledge', it is a persuasive model for understanding the rapid growth in knowledge working that will be discussed later.

Analogous to a Mode 2 perspective, the learning theory Connectivism takes an epistemic stance that knowledge is the collective product of interactions over networks (Siemens 
2005). Making and changing these connections is a core skill, and maintaining interactions across networks to facilitate continual learning is necessary in order to keep knowledge current. Important decisions involved in a process called sensemaking include choosing what and when to learn. Downes (2012) draws a distinction between sensemaking, as a way of understanding and resolving immediate, situation-specific problems, and the lengthier and more reflective process of formal learning, in which the student is typically located at a temporal distance from contexts for knowledge application. Another perspective is that of the useful lifetime of knowledge: in his book The Half-life of Facts, Arbesman (2012) draws a distinction between secure knowledge and the frontier knowledge of research and development that is in rapid flux. In the middle are what he calls mesofacts - such as the number of elements listed in the periodic table - that are subject to occasional change. The idea of knowledge as transient fits well with a Mode 2 view and with the associated perspective of Buckminster Fuller's (1981) Knowledge Doubling Curve: his original estimate was that before 1900 human knowledge was doubling every century, but a recent estimate (Boston Commons 2015) puts this now at every 12 months.

\section{Professional identities and knowledge in the 20th and 21st Centuries}

To the sociologist Basil Bernstein (1971), knowledge and professional identity were intimately related. The identity of practitioners and professionals derived from an 'inwardness' in their commitment to the pure, academic disciplines he called singulars. Complementary to a singular was a region: the outward-facing application of professional knowledge-in-practice. Bernstein saw the preparation for a professional career as more than the acquisition of singular knowledge and an understanding of its application in a region; it was an identity-forging process requiring initiation into a guild with particular beliefs, practices and collective membership - which existed to defend a strictly demarcated occupational territory. As the $21^{\text {st }}$ Century approached, Bernstein (1996) identified a challenge to singulars through the emergence of generic modes as a new kind of knowledge structure that was outward-facing and independent of formal curricula but distinct from the application of specific professional knowledge. These generic modes reflected the demands of graduate employers who called for 'flexibility' in their employees and what are now called transferable skills. Interestingly, this distinction between propositional and procedural ways of viewing knowledge bears similarities with 
the Mode 1 / Mode 2 classification. Related to generic modes was Bernstein's notion of trainability, a preparedness to address new situations and requirements. He saw these moves to genericism as weakening the traditional relationship between academic knowledge and its professional application and challenging conventional conceptions of professional identity. Beck and Young $(2010,190)$ endorse this analysis, citing the recent growth in higher education of what they call generic skills, "... characterized by such terms as 'key skills', 'core skills', 'thinking skills', 'problem solving' and 'teamwork'. They are assumed to apply to all subjects, all regions, all fields of practice and all levels". They see the widely used term 'learning to learn' as essentially the same as Bernstein's trainability, implying a shift from the acquisition of formal knowledge to the development of these generic skills, and conclude by considering the impacts of such developments on the role of the academy. Inasmuch as the main purpose of universities could be said to be the preparation of students for the professions, then the changing nature of professional roles should be reflected by changes in university curricula.

\section{Cooperative working and the knowledge economy}

The term knowledge economy refers to the knowledge-intensive business services that Hertog (2000) sees as significant for innovation and co-production through the interaction of service providers and clients. These knowledge-intensive roles require the abilities to identify and solve problems in situ and to create new knowledge products through the analysis and synthesis of existing information. Eraut (2009) contends that knowledge working should not be viewed solely in terms of competence-based goals, and emphasises the importance of social and emotional components in underpinning personal agency within a community. There is a strong resonance also with Connectivist sensemaking, consonant with a Mode 2 view of knowledge. A fine-grained analysis of knowledge working was made by Reinhardt et al. (2011) through an extensive literature review and examination of data from two empirical studies. The authors identified ten roles of knowledge workers: Controller, Helper, Learner, Linker, Networker, Organizer, Retriever, Sharer, Solver and Tracker. The performance of these knowledge roles involves 13 identified knowledge actions, present in different proportions and represented on an ordinal scale. In particular, the roles of Helper, Linker, Networker, Organizer, Sharer and Tracker have important social and cooperative components. There are interesting comparisons with the work of the Institute for the Future at the University of Phoenix 
(IFTF 2011). Here, ten 'future work skills' were identified, including: Social Intelligence, Virtual Collaboration and Cross Cultural Competency, in addition to the more knowledgefocused skills of Sense-making, Computational Thinking, New Media Literacy and Novel and Adaptive Thinking. A similar research project was the Assessment \& Teaching of 21st Century Skills (ATCS21S 2012), an international grouping headquartered at the University of Melbourne. Following a conceptual scoping exercise the group latterly focused research on the two key skills of Collaborative problem solving and Learning in digital networks. Skills of collaborative working are also evident from the work of DeSeCo (Definition and Selection of Key Competencies), an extensive five-year project of the Organisation for Economic Cooperation and Development, which sought to provide a conceptual framework for the identification of key competencies and dispositions for personal and societal success (Rychen and Salganik 2003). DeSeCo identified three categories: acting autonomously, using tools interactively, and interacting in socially heterogeneous groups. The second of these involved using information and knowledge through technology to identify and solve problems; the third entailed the establishment of good social relations and the skills of cooperation and conflict resolution. Finally, similar competencies and dispositions are reflected in a European Commission study of the views of European teachers and expert panels on the skills related to emerging labour market demands and trends (Redecker et al., 2011). The first of these was personal skills, including initiative, responsibility and creativity; the second was social skills, comprising team working, empathy and co-constructing; and the third was learning skills, including metacognition, organising and managing.

The competencies and dispositions for computer-supported cooperative working identified by various commentators bear many similarities, the most significant of which relate to communication, collaboration, personal qualities and the process skills of knowledge working, and these are reflected in the preferences stated by the employers of graduates. Andrews and Higson (2008) interviewed fifty business graduates and employers in four European countries to identify five sets of competencies and dispositions for graduate employability. In a similar study in the USA (Robles 2012), ninety business executives were asked to list the ten most important soft skills they wanted new employees to possess. The two studies have notable commonalities but also relate closely to the previous taxonomies of computer-supported cooperative working. Table 1 summarises and compares the competencies and dispositions identified in three 
of the computer-supported cooperative working studies with those of the two studies of employers' preferences. Four broad categories have been abstracted in this table: communication, collaboration, initiative \& dependability, and adaptability \& capability, and to these have been mapped equivalent competencies and dispositions from the five studies.

Table 1: A Comparison of Competencies and Dispositions Identified in Knowledge Working and Employers' Preferences Literature

\begin{tabular}{|c|c|c|c|c|c|}
\hline \multirow{2}{*}{$\begin{array}{l}\text { Competency or } \\
\text { Disposition }\end{array}$} & \multicolumn{3}{|c|}{ Knowledge Working (CSCW) Studies } & \multicolumn{2}{|c|}{ Employers' Preferences Studies } \\
\hline & $\begin{array}{l}\text { IFTF } \\
(2011)\end{array}$ & $\begin{array}{l}\text { Reinhardt et al. } \\
\text { (2011) }\end{array}$ & $\begin{array}{c}\text { Rychen and } \\
\text { Salganik (2003) }\end{array}$ & $\begin{array}{l}\text { Andrews and } \\
\text { Higson (2008) }\end{array}$ & $\begin{array}{l}\text { Robles } \\
(2012) \\
\end{array}$ \\
\hline Communication & $\begin{array}{l}\text { Cross cultural } \\
\text { competency }\end{array}$ & $\begin{array}{l}\text { Linker; } \\
\text { Networker; } \\
\text { Sharer; Helper; } \\
\text { Tracker; } \\
\text { Retriever }\end{array}$ & \multirow{2}{*}{$\begin{array}{l}\text { Using tools } \\
\text { interactively; } \\
\text { Interacting in } \\
\text { socially } \\
\text { heterogeneous } \\
\text { groups }\end{array}$} & \multirow{2}{*}{$\begin{array}{c}\text { Effective } \\
\text { communication } \\
\text { \& interaction }\end{array}$} & Communication \\
\hline Collaboration & $\begin{array}{c}\text { Social } \\
\text { intelligence; } \\
\text { Virtual } \\
\text { collaboration }\end{array}$ & & & & $\begin{array}{l}\text { Social skills; } \\
\text { Teamwork; } \\
\text { Courtesy }\end{array}$ \\
\hline $\begin{array}{c}\text { Initiative; } \\
\text { Dependability }\end{array}$ & & $\begin{array}{l}\text { Organizer; } \\
\text { Controller }\end{array}$ & $\begin{array}{c}\text { Acting } \\
\text { autonomously }\end{array}$ & $\begin{array}{c}\text { Self-confidence; } \\
\text { Able to accept } \\
\text { responsibility }\end{array}$ & $\begin{array}{c}\text { Work ethic; } \\
\text { Professionalism; } \\
\text { Positive attitude; } \\
\text { Responsibility; } \\
\text { Integrity }\end{array}$ \\
\hline $\begin{array}{l}\text { Adaptability; } \\
\text { Capability }\end{array}$ & $\begin{array}{c}\text { Novel and } \\
\text { adaptive } \\
\text { thinking; } \\
\text { Sense-making; } \\
\text { Computational } \\
\text { thinking; } \\
\text { New media } \\
\text { literacy }\end{array}$ & $\begin{array}{l}\text { Learner; } \\
\text { Solver }\end{array}$ & & $\begin{array}{l}\text { Able to learn; } \\
\text { Coping with } \\
\text { uncertainty; } \\
\text { Creativity }\end{array}$ & Flexibility \\
\hline
\end{tabular}

The mapping exercise presented in Table 1 shows a degree of concordance within and between the two types of studies as a distillation of expert views on the nature of computer-supported cooperative working and the professional milieu of graduates in the $21^{\text {st }}$ Century. Given the pervasive influence in the Developed World of Information and Communications Technology (ICT) on many aspects of contemporary life, this is unsurprising. What is surprising, however, is the very limited extent to which ICT has permeated the assessment practices of formal, institution-based education. Despite marked changes in the professional identity, knowledge base and practices of workers in graduate occupations compared to their $20^{\text {th }}$ Century predecessors, universities continue 
to focus on assessing the performance of lone individuals. Until recently, this has been constrained by practical necessity, as the assessment of individuals' performance in collaborative groups has been difficult and time-consuming to monitor and assess. The remainder of this paper will address these issues by examining ways in which emerging developments in ICT are making this possible.

\section{Curricula and assessment in universities}

\section{Curricula and authentic learning}

The epistemic focus of traditional university curricula has been the transmission of formal, Mode 1 knowledge. Organised by subject disciplines, this knowledge has undergone a process of filtering and sublimation into distinctive conceptual structures with an internal logic that makes it (complex but) relatively straightforward to teach. However, the shrinking half-life of knowledge and exponential growth of frontier knowledge (Arbesman 2012) through ICT-enabled $21^{\text {st }}$ Century working present a significant challenge to the utility of formal knowledge, not only in its currency but in its orientation. Mode 2 knowledge and the constellation of working practices around computer-supported cooperative working are situated in the workplace and not the academy. The imperative here is the very practical one of sensemaking and solution rather than a reflective concern for the integrity of pure knowledge that stands apart from its application. A further difference lies in the practices of new knowledge working, which engage a range of personal qualities and dispositions as identified in Table 1; by contrast, the study of formal knowledge is a solitary and cerebral affair.

If the curricula of universities are to embrace these changes then rebalancing will be needed. More learning experiences must be sited outside the institution and these experiences should include opportunities for students to develop as accomplished team players. Lombardi $(2007,3)$ makes a well-argued case for authentic learning to establish 'real-world' relevance and presents a distillation of learning research in the form of ten 'design elements', summarised below.

1. Real-world relevance: the need for authentic activities within a realistic context. 
2. III-defined problem: confronting challenges that may be open to multiple interpretations.

3. Sustained investigation: undertaking complex tasks over a realistic period of time.

4. Multiple sources and perspectives: employing a variety of perspectives to locate relevant and useful resources.

5. Collaboration: achieving success through division of labour and team working.

6. Reflection (metacognition): reflection upon individual and team decisions.

7. Interdisciplinary perspective: encouraging the adoption of diverse roles and thinking.

8. Integrated assessment: coinciding the learning process with feedback that reflects real-world evaluation.

9. Polished products: achieving real and complete outcomes rather than completing partial exercises.

10. Multiple interpretations and outcomes: appreciating diverse interpretations and competing solutions.

\section{Authentic learning in practice}

Many universities have already taken steps to accommodate authentic learning, creating degree courses with more vocational focus and employing ICT in various ways to extend learning beyond the institution. Work placements are a common feature of many university courses, with evidence they are valued by students. In research by Crebert et al. (2004) at Griffith University in Australia, graduates considered the experience of team working and collaborative learning during their work placements as being of particular benefit in preparing them for employment. In the UK, research at the University of Reading has informed an extensive toolkit of resources (CCMS 2009) to support external engagement and work-related learning. However, such initiatives are small-scale in comparison to the transformative changes made in the three examples to be discussed. The first is Alverno College, a small, liberal arts institution in Wisconsin, USA, which has centred its curriculum around eight Core Abilities (Alverno 2011) including:

- Communication: '... the ability to speak, read, write and listen clearly, in person and through electronic media'. 
- Problem solving: '... define problems and integrate resources to reach decisions, make recommendations or implement action plans'.

- Social interaction: '... the ability to elicit other views, mediate disagreements and help reach conclusions in group settings'.

- Analysis: '... the ability to use experience, knowledge, reason and belief to form carefully considered judgments'.

In a comparable way, the curriculum at Evergreen State College in Olympia, Washington State, USA, has been designed with five Foci of Learning (Evergreen 2016) including:

- Interdisciplinary Study: 'Students learn to pull together ideas and concepts from many subject areas, which enables them to tackle real-world issues in all their complexity.'

- Collaborative Learning: 'Students develop knowledge and skills through shared learning, rather than learning in isolation and in competition with others.'

- Personal Engagement: 'Students develop their capacities to judge, speak and act on the basis of their own reasoned beliefs.'

- Linking Theory with Practical Applications: 'Students understand abstract theories by applying them to projects and activities and by putting them into practice in real-world situations.'

Roskilde University in Denmark (RUC 2016) also values interdisciplinarity and collaborative learning, with $50 \%$ of learning time devoted to problem-oriented project work conducted in small groups. Projects extend over three months, examining realworld issues but defined by students' interests, and groups are encouraged and supported to collaborate with external organisations.

The curricula of Alverno, Evergreen and Roskilde invite interesting comparisons with Lombardi's ten design elements and the qualities presented in Table 1, and they are proof of the feasibility of such approaches. However, all three institutions are small and specialist, drawing students attracted by their special offering. It is also likely that teaching staff have been attracted for the same reason, with the result that the problems of assessing authentic learning - to be discussed in the next section - might be more readily addressed. In addition, all three institutions have changed the content and process of their assessment. Alverno College employs narrative transcripts rather than the widespread practice of Grade Point Average scores to profile students' achievements. At Evergreen a Collaborative Assessment Protocol defines a qualitative process to 
evaluate students' group work, and at Roskilde the unique nature of each project demands a comparable approach. It appears that changing assessment practices might have proved necessary in order to meet the needs of transformed curricula. This raises the question of whether the achievements of these small, niche institutions can be scalable to the high-volume demands of mainstream higher education.

\section{Assessing authentic learning}

The assessment of Mode 2 knowledge is 'untidy' and problematic. To assess Mode 1 knowledge, universities have traditionally been concerned more with individual students' understanding of precepts and principles and how to 'decode the discipline' (Pace and Middendorf 2004) than with application in real-world contexts. The assessment methods employed have been relatively 'tidy' and have sought as far as possible to control and standardise in the form of summative statements of individual students' achievements against level descriptors. However, Sadler (2014) notes largely uncritical assumptions that codified academic achievement standards can support 'objective' assessment and argues that such an approach is fundamentally flawed. To assess Mode 2 knowledge, methods must be situated in contexts for application, so must be adaptive to the diverse and complex unpredictability of real-world environments. The assessment of such activities is not tidily summative, but may involve the need for ongoing feedback and closer integration with the process of learning. As Williams (2014) discusses, what is called alternative assessment has the benefit of providing formative feedback: an assessment for learning rather than the summative assessment of learning (Sambell et al. 2013). This shorter distance between performance and assessment is important in knowledge working where agendas for appraisal and decision-making are more likely to be determined by the environments in which learning is situated. Methods associated with this more closely integrated assessment include e-portfolios and reflective logs (Dyment and O'Connell 2011) to relate assessment more appropriately to students' particular experiences. These methods fit well with approaches such as enquiry-based learning (Deignan 2009) and project-based learning (Bell 2010). However, whilst this can result in learning that is rich and relevant, such approaches have proved very difficult to quality control in the way that Mode 1 learning can traditionally be taught and assessed. Williams (2008) examines a number of reasons for this, including the considerable time and effort involved in preparing and managing student-centred learning and in the 
difficulty of deciding assessment criteria and separating task outcomes from student performance. When the issue of monitoring and assessing students' learning in collaborative situations is factored in, this already involuted task becomes daunting.

The notion of authentic assessment is defined by Gulikers et al. $(2004,69)$ as: 'an assessment requiring students to use the same competencies, or combinations of knowledge, skills, and attitudes that they need to apply in the criterion situation in professional life'. In higher education, authentic assessment derives from the application of alternative assessment approaches to learning situated in contexts closely similar to those to which a course is oriented. Authentic assessment can also be undertaken in simulated contexts such as those of problem-based learning, and examples are to be found at Alverno, Evergreen and Roskilde. In the conceptual model devised by Williams $(2014,570)$, the goal is to coincide assessment with the learning process in order to maximise the potential of formative feedback. As more course content and learning resources in universities are made available online, the opportunities for employing this mode of learning will grow - as will the need for effective methods for its assessment.

In the next section of the paper the emerging technology of learning analytics will be evaluated to gauge its potential utility in the authentic assessment of situated, collaborative learning in mainstream higher education.

\section{Big data and learning analytics}

Employed in almost every university in the world, virtual learning environments (VLEs) otherwise known as learning management systems - provide vast storage silos of students' online learning activity. Within most VLEs are software tools providing a basic statistical breakdown of this activity, but many are awkward to use and have limited scope. learning analytics was developed in business intelligence environments where the monitoring and interpretation of vast amounts of machine-readable data provided competitive advantage. Its use extended to healthcare and from there to mainstream higher education, where the related field of educational data mining of big datasets of online activity provides far more sophisticated and large-scale profiling of students' progress than is possible with VLE tools. A successful early example in higher education is 
the Course Signals system developed at Purdue University in the USA (Arnold and Pistilli 2012), where analyses of students' progress are presented in a simple traffic lights dashboard to show whether progress is satisfactory, at mild risk or urgent risk, in order to trigger interventions by academic teachers as early as possible in a course. Course Signals operates on online activity and progress data using student success algorithms to compare a student's profile with benchmarked profiles of students successful in the past. According to Arnold and Pistilli (ibid.) its main benefits include improvement in students' motivation and performance in meeting course targets, and significant improvements in student retention. learning analytics activity in Higher Education has burgeoned, becoming the focus of extensive academic study. Recent developments in the UK include a collaborative project involving over 50 universities and colleges supported by the notfor-profit organisation, Jisc (2016).

\section{Social learning analytics}

More complex and sophisticated techniques are under development that employ discourse analytics, content analytics and dispositions analytics on student collaboration data (Ferguson 2012). The goal is social learning analytics, an approach proposed by Buckingham Shum and Ferguson (2012) to model affective aspects of the learning process through student interactions and learning in social contexts. Learning dispositions are defined by Buckingham Shum and Deakin Crick (2012) as relatively enduring propensities that reflect individuals' personal awareness as learners and their engagement with others in learning relationships and with new learning opportunities. They go on to propose a dispositions analytics framework using data generated from learning activity together with learning dispositions, values and attitudes measured through self-report surveys. Social learning analytics differs from its business intelligence precursors in being informed by learning theory, particularly in the use of language for the co-construction of knowledge in collaborative working environments where learners are viewed as social actors in complex networks. The analysis of this process is also highly complex - as can be seen in recent research into the assessment of collaborative conversations and knowledge-building discourse within project teams (for example, Gahgene et al. 2011; Ferguson and Buckingham Shum 2012; Dascalu et al. 2013). 
Where the 'first generation' of learning analytics was the provision of student performance data to academic teachers, the second involves social learning analytics in the provision of ongoing feedback to students. Feedback as a formative agent for effective learning is discussed earlier alongside concerns about the difficulties of setting up authentic learning contexts in which reliable assessment and feedback is readily available, especially in environments involving collaborative learning. Dashboards providing graphical summaries of analytics data to academic teachers can also supply timely formative feedback to students. Aljohani and Davis (2013) report the trial of such an application with a group of 72 university students. The dashboard was created for smartphones as well as conventional computers to provide students with immediate feedback on a weekly quiz. This included performance relative to the class average and itemised results in relation to question difficulty. A significant majority of students in the study reported that the flexibility of mobile access to detailed feedback was a formative motivator. Ongoing feedback for learners was also the focus of an empirical study by Tempelaar et al. (2015). Drawing upon the dispositions analytics framework proposed by Buckingham Shum and Deakin Crick (2012) (introduced earlier), the authors collected a range of learner data from over 900 university students engaged in a module delivered by blended learning. Assessments of students' learning dispositions were accompanied by performance data from quizzes and other types of online activity. The authors concluded that a mix of dispositional and performance data provided the best prediction of final outcomes. Looking to the future, if it proves possible to improve the reliability of assessment and the quality and frequency of feedback, then the door is opened to the greater employment of collaborative learning in authentic contexts.

\section{Key implications for universities}

\section{Concerns}

As the adoption of learning analytics moves from periphery to mainstream in higher education a number of concerns are being voiced. Discussed here are the power relationship between students and institutions, with related ethical issues, and some implications for the preparedness and expertise that would be required of academic teachers. 
All educational approaches carry some assumptions, and Amory (2010) argues that ideological contradictions are present in the use of new technologies for learning. For example, to use technology as an information delivery tool to support conventional teaching - embodied in presentation software, interactive whiteboards and lecture capture systems - is in conflict with using technology in social and collaborative ways for the development of learners' personal growth and identity. Epistemic assumptions of this first kind seem inherent in the employment of learning analytics as systems to alert institutions to students who deviate from the norm and who require teaching interventions. In the view of Campbell (EDUCAUSE 2012), such simplistic measurements of observable activity and individuals' achievements neglect wider issues of affective and personal development, and Lynch (ibid.) is concerned that heavy-handed interventions might jeopardise students' ownership of their studies and discourage risk-taking and individuality. Related to these concerns are the ethical issues of data protection and privacy. Willis et al. (2013) examine what they call the ethical dilemma of analytics. They emphasise that students' rights to ownership of their data must be preserved and they identify responsibilities and recommendations for institutions. In the UK, the recent ethical code of practice developed by Jisc (2015) makes similar recommendations that are likely to be adopted by many universities.

Another concern is the demands that these new ways of working would make of students and their academic teachers. Moving to second generation social learning analytics would require in academic teachers a greater preparedness and more detailed understanding of the processes of individual and collaborative learning and formative assessment than may currently be the norm. Examples of the sort of demands likely to be made can be found in Sadler's (2015) recommendations for three reforms for universities to improve teaching quality through the effectiveness of assessment: designing assessment tasks, defining minimum requirements for a pass grade, and crediting the outcomes of formative assessments. Sadler's advice for the first of these reforms includes the creation of simulated or real-life problems that require applied and higher order thought processes. There are close similarities here to authentic learning, but as Williams (2008) cautions, deciding assessment criteria that distinguish task outcomes from student performance is far from easy. The second reform involves the difficulty of establishing grade descriptions that will be consistently employed across a range of 
examiners; as discussed earlier, Sadler (2014) regards this as particularly problematic. The third proposed reform advises the clear separation of marks awarded for formative tasks from the summative assessment of a course. Again, real-life contexts for these tasks are recommended. All three of Sadler's reforms would require students to take more responsibility for their learning, and academic teachers would need to engage pedagogically at a higher level of concern and understanding. Implementing Social learning analytics might require comparable or even greater levels of understanding and commitment.

\section{Opportunities}

Social learning analytics have the potential to extend new opportunities to mainstream universities, and two possibilities are discussed in the remainder of this section.

Firstly, a move from quantifying the performance of individual students on academic exercises to the analysis of collective group achievements on authentic tasks involving soft skills would shift the assessment focus from individuals to groups. From the analysis of such achievements it would also be possible to produce rich narrative transcripts, along the lines of Alverno College, to profile students as whole persons - in contrast to the present reliance on aggregating numerical grades. Many universities are already developing more detailed graduate profiles, and the Higher Education Achievement Report (HEAR 2015) in the UK provides a practical format. More inclusive warranting would be possible through the assembly by graduates of comprehensive portfolios to evidence their talents and achievements as team members. Such evidence could serve a variety of purposes as a useful supplement to the certification of individual academic success.

A second possibility for radical transformation is a move to more flexible study patterns and the siting of learning. Situating learning experiences outside the institution erodes the boundary between university and external organisations, an example of this being the employer partnerships pioneered at Roskilde University. However, the monitoring of students' progress and achievement in work placements is problematic, and Benett (1993) outlines a number of difficulties in making valid and reliable assessments and selfassessments in what are complex and diverse environments. As discussed earlier, 
learning analytics has the potential to supplement existing methods of assessment. This more flexible and fine-grained monitoring would enable external engagement to be scheduled more naturally within project timescales that might not fit within university semesters; a more flexible structuring of degree courses might therefore be possible. Breaking away from the constraints of traditional three- or four-year full-time models and 'just-in-case' learning, it might become feasible to offer learning experiences that would be adaptive, asynchronous, multiply-sited, multiply-authored and jointly managed within learning partnerships.

\section{Conclusion and Recommendations}

Three significant and inter-related issues for higher education have been examined in this paper. The first was the rise of knowledge working and the impacts on universities made by Mode 2 knowledge and computer-supported cooperative working. The second issue explored responses to these impacts through the employment of authentic contexts and computer-supported collaborative learning. The benefits of these approaches are considerable, but so are the difficulties of assessment. The final issue was the opportunities provided by social learning analytics to bring authentic assessment - and therefore authentic learning - further into mainstream higher education.

University leaders face pivotal strategic decisions as to how they might deploy learning analytics: either to exercise restrictive management and control, or to enhance the educational and personal development of their students. This dichotomy reflects assumptions about the epistemic nature of education and the purpose of universities. On the one hand, if university degrees are regarded as standardised products to be delivered to customers with maximum efficiency and student retention, then the mass analysis of student activity data to quantify and warrant this process is an appropriate strategy. On the other hand, if the academy is viewed primarily as a place of personal and collegial growth through learning - where outcomes are harder to quantify and warrant - then the potential of social learning analytics to support these practices is far reaching and possibly transformative. It is the strong contention of this paper that the latter option should be taken. To deploy the considerable potential of social learning analytics to support and evaluate students' collaborative learning in realistic contexts sits squarely 
within the liberal tradition of Newman (1852) and Dewey (1938), who saw education as a progressive, personal and social force that primarily should serve the needs of learners. Moreover, such a strategy acknowledges and engages very well with the changing environment in which universities operate and with the new professional milieu of graduates in the $21^{\text {st }}$ Century.

\section{References}

Aljohani, N. and H. Davis. 2013. "Learning analytics and formative assessment to provide immediate detailed feedback using a student centered mobile dashboard." Paper presented at the 7th International Conference on Next Generation Mobile Apps, Services and Technologies (NGMAST'13), Praha, Czech Republic, September.

Alverno. 2011. The 8 Core Abilities, Alverno College. http://www.alverno.edu Amory, A. 2010. "Education technology and hidden ideological contradictions." Educational Technology \& Society 13: 69-79.

Andrews, J. and H. Higson. 2008. "Graduate employability, 'soft skills' versus 'hard' business knowledge: a European study." Higher Education in Europe 33: 411-422.

Arbesman. 2012. The Half-life of Facts: Why Everything We Know Has an Expiration Date, New York, NY: Penguin Group.

Arnold, K. and M. Pistilli. 2012. "Course Signals at Purdue: using learning analytics to increase student success." In Proceedings of the 2nd International Conference on learning analytics and Knowledge. New York, NY: ACM.

ATC21S. 2012. Assessment \& Teaching of 21st Century Skills. http://atc21s.org

Barnett, R. 2000. "University knowledge in an age of supercomplexity." Higher Education 40: 409-422.

Beck, J. and M. Young. 2010. "The assault on the professions and the restructuring of academic and professional Identities: a Bernsteinian analysis." British Journal of Sociology of Education 26: 183-197.

Bell, S. 2010. "Project-based learning for the 21st Century: skills for the future." The Clearing House 83: 39-43.

Benett, Y. 1993. "The validity and reliability of assessments and self-assessments of workbased Learning." Assessment \& Evaluation in Higher Education 18: 83-94. 
Bernstein, B. 1971. "On the classification and framing of educational knowledge." Knowledge and Control 3: 245-270.

Bernstein, B. 1996. Pedagogy, symbolic control and identity: theory, research and critique. London: Taylor and Francis.

Boston Commons. 2015. Knowledge Doubling. Boston Commons High Tech Network, 10 December. http://www.bostoncommons.net/knowledge-doubling/

Buckingham Shum, S., and R. Ferguson. 2012. "Social learning analytics." Educational Technology \& Society 15 (3), 3-26.

Buckingham Shum, S., and R. Deakin Crick. 2012. "Learning dispositions and transferable competencies: Pedagogy, modelling and learning analytics". Paper presented at the 2nd International Conference on learning analytics \& Knowledge, Vancouver, British Columbia, April.

Buckminster Fuller, R. 1981. Critical Path. New York, NY: St Martins Press.

CCMS. 2009. Engaging Employers to Enhance Teaching and Learning: ideas and approaches for work-related and placement learning, Centre for Career Management Skills, University of Reading, UK.

http://www.reading.ac.uk/web/FILES/ccms/B02056 Employment Engagment AS V6 . $\mathrm{pdf}$

Crebert, G., M. Bates, B. Bella, C-J. Patrick and V. Cragnolini. 2004. "Developing generic skills at university, during work placement and in employment: graduates' perceptions." Higher Education Research \& Development 23: 147-165.

Dascalu, M., S. Trausan-Matu and P. Dessus. 2013. "Cohesion-based analysis of computer-supported collaborative learning conversations: holistic and individual perspectives." computer-supported collaborative learning 2013 Proceedings: 145-152, Computer Supported Collaborative Learning Conference, Madison, USA.

Deignan, T. 2009. "Enquiry-based learning: perspectives on practice." Teaching in Higher Education 14: 13-28.

Dewey, J. 1938. Experience \& Education. New York: Kappa Delta Pi.

Downes, S. 2012. "Change MOOC: sensemaking and analytics." Connectivism (April 24th). http://www.connectivism.ca

Dyment, J. and T. O'Connell. 2011. "Assessing the quality of reflection in student journals: a review of the research." Teaching in Higher Education 16: 81-97.

EDUCAUSE. 2012. Analytics Examined, EDUCAUSE Channel, You Tube. https://www.youtube.com/watch?v=4rMvOwCNZQI 
Eraut, M. 2009. "The balance between communities and personal agency: transferring and integrating knowledge and know-how between different communities and contexts." Chap. D3 in Norman Jackson, ed. 2012. Learning to be Professional through a Higher Education e-book. http://learningtobeprofessional.pbworks.com/f/michael+eraut+D3.pdf

Evergreen. 2016. The Five Foci of Learning, The Evergreen State College. http://evergreen.edu/about/fivefoci.htm

Ferguson, R. 2012. "The state of learning analytics in 2012: a review and future challenge. Technical Report KMI-12-01, Knowledge Media Institute." The Open University, UK.

Ferguson, R. and S. Buckingham Shum. 2012. "Social learning analytics: five approaches." Proceedings of the 2nd International Conference on learning analytics \& Knowledge: 23-33, Vancouver, Canada.

Gahgene, G., P. Agrawal, M. Udani, B. Raj and C. Rose, C. 2011. "The automatic assessment of knowledge integration processes in project teams." computersupported collaborative learning 2011 Proceedings: 462-469, Computer Supported Collaborative Learning Conference, Hong Kong, China.

Gibbons, M., C. Limoges, H. Nowotny, P. Scott, S. Schwartzman, and M. Trow. 1994. The New Production of Knowledge - the dynamics of science and research in contemporary societies. London, UK: Sage.

Gulikers, J., T. Bastiaens and P. Kirschner. 2004. "A five-dimensional framework for authentic assessment." Educational Technology Research and Development 52: 67-85.

Hertog, P. 2000. "Knowledge-intensive business services as co-producers of innovation." International Journal of Innovation Management 4: 491-528.

Hessels, L. and H. van Lente. 2008. "Re-thinking new knowledge production: a literature review and a research agenda." Research Policy 37: 740-760.

HEAR. 2015. Higher Education Achievement Report. York, UK: Higher Education Academy. IFTF. 2011. Future Work Skills 2020, Institute for the Future, University of Phoenix, USA. http://www.iftf.org/futureworkskills/

Jisc. 2015. Code of practice for learning analytics. https://www.jisc.ac.uk/guides/code-of-practice-for-learning-analytics Jisc. 2016. Effective learning analytics project. https://www.jisc.ac.uk/rd/projects/effective-learning-analytics Lombardi, M. 2007. Authentic Learning for the 21st Century: an overview. ELI Paper 1, EDUCAUSE. 
Newman, J. 1852. The Idea of a University. London: Longmans, Green \& Co.

Nowotny, H. 2003. "Democratising expertise and socially robust knowledge." Science and Public Policy 30: 151-156.

Pace, D. and J. Middendorf (Eds) 2004. “Decoding the disciplines: helping students learn disciplinary ways of thinking." New Directions for Teaching and Learning, 98. San Francisco, USA: Jossey Bass.

Redecker, C., M. Leis, M. Leendertse, Y. Punie, G. Gijsbers, P. Kirchner, S. Stoyanov and B. Hoogveld. 2011. The Future of Learning: Preparing for Change, Institute for Prospective Technological Studies. Luxembourg: European Commission.

Reinhardt, W., B. Schmidt, P. Sloep and H. Drachsler. 2011. "Knowledge worker roles and actions - results of two empirical studies." Knowledge and Process Management 18: 150-174.

Robles, M. 2012. “Executive Perceptions of the Top 10 Soft Skills Needed in Today's Workplace." Business Communication Quarterly 75: 453-465.

RUC. 2016. Education, Roskilde Universitet, Denmark. http://www.ruc.dk/en/education/ Rychen, D. and L. Salganik. (Eds) 2003. Key Competencies for a Successful Life and a WellFunctioning Society. Göttingen, Germany: Hogrefe Publishing.

Sadler, D. R. 2014. "The futility of attempting to codify academic achievement standards". Higher Education 67: 273-288.

Sadler, D.R. 2015. "Three in-course assessment reforms to improve higher education learning outcomes". Assessment \& Evaluation in Higher Education. Published online: 17 Jul 2015. DOI: 10.1080/02602938.2015.1064858

Sambell, K., L. McDowell and C. Montgomery. 2013. Assessment for Learning in Higher Education. Abingdon, UK: Routledge.

Schön, D. 1983. The Reflective Practitioner: how professionals think in action. New York, NY: Basic Books.

Siemens, G. 2005. "Connectivism: a learning theory for the digital age." International Journal of Instructional Technology \& Distance Learning 2 (1) [unpaged].

Tempelaar, D., B. Rienties and B. Giesbers. 2015. "In search for the most informative data for feedback generation: learning analytics in a data-rich context." Computers in Human Behavior 47: 157-167.

Usher, R. 2010. "A diversity of doctorates: fitness for the knowledge economy?" Higher Education Research \& Development 21: 143-153. 
Williams, P. 2008. "Assessing context based learning: not only rigorous but also relevant." Assessment \& Evaluation in Higher Education 33: 395-408.

Williams, P. 2014. "Squaring the circle: a new alternative to alternative-assessment." Teaching in Higher Education 19: 565-577.

Willis, J., Pistilli, M. and J. Campbell. 2013. "Ethics, big data, and analytics: a model for application." EDUCAUSE Review Online, 6 May.

http://er.educause.edu/articles/2013/5/ethics-big-data-and-analytics-a-model-forapplication 